\title{
War, politics, and osteopathic medicine
}

\author{
MURRAY GOLDSTEIN, DO, MPH
}

About history the question can always be asked, Do scholars document historical events or do they create history by selective reporting? The history of the origins of osteopathic medicine and the forces that motivated Andrew Taylor Still are steeped both in anecdotes from his contemporaries and in post hoc interpretations of past events. One important question is, Where or how did Dr Still come to formulate the ideas underlying osteopathic principles? Were the principles uniquely his? Another is, Why has osteopathic medicine flourished when other "schools of medical concepts" have languished and died? I suggest that, over the centuries, war and the military have played critical roles both in the development of manipulative treatment and in the establishment of osteopathic medicine as a legitimate and necessary part of the healing arts.

\section{Ancient times}

Manipulative treatment was well established in ancient times. In the second century, the Greek physician and author Galen mentions a case reported by Hippocrates some 5 centuries earlier: A man who had fallen off a cart

Dr Goldstein is director, National Institute of Neurological Disorders and Stroke, National Institutes of Health, Public Health Service, Department of Health and Human Services, Bethesda, Md. His opinions and comments are personal and do not necessarily represent those of the Department of Health and Human Services.

Reprint requests to Murray Goldstein, DO, MPH, director, National Institute of Neurological Disorders and Stroke, NIH, Bldg 31, Rm 8A52, 9000 Rockville Pike, Bethesda, MD 20892. a month earlier had developed pins and needles with numbness in the third, fourth, and fifth fingers of his left hand. Hippocrates localized the injury "to the spinal nerve below the seventh cervical vertebra and cured the patient by treating his neck." Hippocrates might well have qualified for membership in the American Academy of Osteopathy.

With the fall of Rome and the decline of European culture, records of medical advances became exceedingly thin. Because religious dogma dominated nearly all aspects of scientific thought, medicine was more spiritual than it was biological. However, during the Dark Ages of Europe, medical inquiry was flourishing in the Middle East-in what is today Turkey, Syria, and Lebanon.

\section{The Crusades and Avicenna's Canon of Medicine}

In the Crusades, which took place during the 11 th to 13 th centuries, Europeans of many nations invaded the Middle East. Despite a rather ignoble military record, the Crusaders brought back to a benighted Europe the jewels of Islamic culture.

Among the treasures brought back from the Crusades was Avicenna's Canon of Medicine, one of the most important books in the history of medicine. Avicenna (ibn Sina), a Persian physician and among the most famous and influential of the philosopher-scientists of Islam, had based this systematic encyclopedia on the achievements of Greek physicians of the Roman imperial age, on other Arabic works, and, to a lesser extent, on his own experience. 
This compendium was to be reprinted many times in Latin and to remain an authoritative medical textbook in Europe until the 17th century. Avicenna's Canon included a number of illustrations of manipulative treatment, with descriptions of its indications and expected therapeutic results. Thus, the Crusades - a forerunner of world wars-led to the reintroduction into Europe from an Islamic repository of the principles of manipulative treatment, described centuries earlier by Hippocrates and his pupils.

\section{The Renaissance}

Throughout the Renaissance, manipulative treatment was practiced by both physicians and laymen. But let's get closer to home. Manipulative treatment made a great impact in 18th-century England, where the most renowned lay bonesetter of the day was Mrs Sarah Mapp, more commonly known as "Crosseyed Sally." Of her the London Magazine wrote on Aug 2, 1736: "The town has been surprised lately with the fame of a young woman at Epson, who though not very regular in her conduct, has wrought such cures that seem miraculous." On Aug 19 of the same year in the London Magazine, we read: "Mrs. Mapp, the famous bone-setter at Epson, continues making extraordinary cures; this day she came to Kensington and waited on her Majesty."

In addition, a song was composed in praise of cross-eyed Sally:

You surgeons of London who puzzle your pates

To ride in your coaches and purchase estates; Give over for shame, for your pride has a fall The doctress of Epson has outdone you all. ${ }^{2(\mathrm{p} 31)}$

\section{Nineteenth-century England: Spinal physiology and bonesetting}

In 19th-century England, medical science was characterized by an increased interest in the spinal cord. It was proposed at that time that the spinal cord, like the brain, had a cognitive function; it was part of the mind. It was also established that anatomic disturbances and pathologic conditions of the cord would lead to both muscle and visceral dysfunctions.
Concurrently, the clinical results of the lay bonesetter began to interest the more thoughtful members of the English medical establishment. For example, in a lecture at St Bartholomew's Hospital in 1866, the surgeon Sir James Paget said: "Few of you are likely to practice without having a bone-setter for an enemy. Now, it would be of little use to us to estimate the quantity of mischief done by treatment such as this. It is more important to know and consider that it sometimes does good."2(pp32,33)

\section{The US Civil War, Dr Still, and osteopathy}

Thus, with the developments in spinal physiology and the establishment of the lay bonesetter as a clinician, the stage was set for a transatlantic leap of medical interest in the spine to the United States during the Civil War.

Osteopathy was established in the United States by Andrew Taylor Still, MD, in 1892. Like many physicians of his time, Dr Still was disturbed about the state of medical therapy, particularly about the inadequacy and danger of the available pharmacopia. After the death of three of his children due to cerebrospinal meningitis, he is said to have rallied against the "indiscriminate use of drugs." But where did he find manipulative treatment? There is no indication that it was used by Dr Still's father, a missionary physician who worked among the Indians of the Middle West. Nor is it likely that it came to him in a spiritual revelation, although Dr Still was a profoundly religious man. However, Dr Still had served in the Ninth Kansas Cavalry and later during the Civil War in the 21st Kansas Militia of the Union Army.

We know that both the Union and Confederate armies were well endowed with English physicians, who found the Civil War an exciting occasion to practice their skills and to escape the genteel establishment that dominated 19th-century English medicine. The English physicians and the American physicians from the larger eastern cities must have certainly used this opportunity to acquaint their country cousins with the wonders of modern Eng- 
lish medical science and to share with them their copies of Lancet and the British Medical Journal, in both of which prestigious journals the debate was flourishing about the results obtained by lay bonesetters.

Did Dr Still learn about manipulative treatment from these medical officers and their journals-journals with which a frontier doctor would probably have had minimal previous contact and could now have found to be exciting reading?

Did the young physician, dissatisfied with emetics, purgatives, herbs, opiates, bloodletting, and coarse surgery, find manipulative treatment in the Civil War?

Dr Still was not alone in his dissatisfaction with 19 th-century medicine. In frustration, his renowned contemporary Dr Oliver Wendell Holmes, Sr, of Boston, had fulminated, "If the whole materia medica as now used could be sunk to the bottom of the sea, it would be better for mankind-and all the worse for the fishes."Another contemporary, Dr William Osler, who was sometimes considered a "therapeutic nihilist" by his contemporaries, had expressed serious reservations about the available pharmacopia and actively sought other therapeutic modalities. (See the October 1988 issue of JAOA for Suter's review of the philosophic relationship between Hippocrates, Osler, and Still. ${ }^{3}$ )

\section{World War II, DOs, and the home front}

In the 76 years between the end of the Civil War and the beginning of US involvement in World War II, osteopathic medicine had a rough time. As allopathic medicine was being organized on the state level and then on the national level, the DO was labeled naturopath, drugless practitioner, cultist, and charlatan. This was particularly true after the release in 1910 of the Flexner report, ${ }^{4}$ which set standards for medical education that damned the educational program of many medical schools as well as osteopathic medical schools. As a result, there was a reformation in osteopathic medical educational standards and a painfully slow increase in practice privileges.

With the coming of World War II, organ- ized medicine in the United States was faced with a dilemma. Medical physicians were being drafted into the military to serve US troops, and the civilian population had to do the best it could with what was left. It was unacceptable to the medical profession and to military medical leaders that osteopaths should be commissioned as medical officers and work as equals alongside "real doctors."

Thus, medical physicians were drafted, and osteopaths were left at home- but left at home to take care of the civilian population, particularly in rural areas and small towns. A stellar performance in filling this healthcare need led to the osteopath becoming the osteopathic physician. Because osteopathic physicians were excluded from all medical hospitals and patients needed to be admitted for hospital care, particularly for surgery, osteopathic hospitals proliferated and prospered. Thus, World War II was a singularly important event in the establishment of osteopathic physicians as peers to medical physicians.

\section{The Eisenhower years, DOs, and a federal appointment for a DO}

The acceptance of osteopathic medicine at the national level had to await Kenneth Riland, DO, who prior to his death in 1989 had practiced occupational osteopathic medicine in New York, with an emphasis on manipulative treatment. Dr Riland was the personal physician of Nelson Rockefeller, who was later to become governor of New York. In the early 1950s, Rockefeller became undersecretary of the then US Department of Health, Education, and Welfare (HEW) and as such was responsible for the day-to-day operation of that very large, important department of the government.

In 1952, Dr Riland convinced Undersecretary Rockefeller that the time had come to challenge the blackball still in effect against appointing osteopathic physicians to the uniformed services. They decided that the Public Health Service, an arm of HEW, would be the appropriate organization in which to accomplish this and selected a DO candidate for appointment. Recognizing the potential criticism 
from organized medicine, Rockefeller spoke to President Eisenhower about the appointment. Dr Riland told me that the President said, "If he is qualified, appoint him. I will handle the politics."

In 1953, an osteopathic physician was appointed a medical officer in the uniformed services of the United States. You know the rest of the story: osteopathic physicians are now employed in every part of the federal establishment and participate in the setting of national health policies for both the military and the public sectors.

\section{The future}

What role can we expect war and the military to play in the future of our profession? None, I hope. Nevertheless, despite our aversion to war and its senseless suffering, our own roots and development have been linked with it throughout the centuries. I have traced the connection between our profession and the military to illustrate that manipulative treatment, a hallmark of osteopathic medicine, is an ancient and international medical art. We osteopathic physicians maintain a time-honored clinical tradition. Let us be proud of it.

With our colleagues in allopathic medicine, we must now address ourselves to the healthcare problems confronting our nation and find ways to improve healthcare services.
As part of that responsibility, we need to be critical—constructively critical-of our osteopathic principles and practices. Modern medical science demands that we reevaluate our principles. From a rich heritage from the past, Dr Still synthesized the system of clinical principles on which our profession is based. With professional acceptance comes the professional responsibility of evaluating those principles by modern scientific and clinical standards. We need not wait for another war to take this important next step.

Much of the pre-Civil War historical information was taken from: Manipulation: Past and Present, by E.H. Schiotz and J. Cyriax, Heineman Medical Books, London, 1975. Also information about Dr A.T. Still was taken from History of Osteopathy and Twentieth Century Medical Practice, by E.R. Booth, Caxton Press, Cincinnati, 1924, and from The D.O.'s: Osteopathic Medicine in America, by N. Gevitz, The Johns Hopkins University Press, Baltimore, 1982.

1. Galenus: Opera, vol IV, Venice 1625; De locis affectis, Libre I, Chapt 6; Renander A (trans [Swedish] Om sjukdomarnas lokalisation). Stockholm, Sweden, 1960, pp 152-155.

2. Schiotz EH, Cyriax J: Manipulation: Past and Present. London, Heinemann Medical Books, 1975, pp 31-33.

3. Suter RE: Hippocratic thought: Its relationship to and between Andrew Taylor Still and Sir William Osler. JAOA 1988;88:1243-1254.

4. Flexner A: Medical Education in the United States and Canada: A Report to the Carnegie Foundation for the Advancement of Teaching. Boston, The Merrymount Press, 1910. 